\title{
Serial sampling provides chronological evidence that endogenous protein is used for primary growth in a molt- migrant goose
}

Sievert Rohwer, Anthony D Fox, Thomas Daniel, Jeffrey F Kelly

This is a proof of concept paper based on chronological samples of growing feathers from geese thought to be molt-migrants. When molt-migrant birds initiate molt shortly after migrating to a new isoscape, isotope values measured along the length of their feathers should change continuously. To assess long-term changes and daily cycling in $\delta^{15} \mathrm{~N}$ and $\delta^{13} \mathrm{C}$ values, we serially sampled growing primaries of three presumed molt-migrant geese. Two showed changing $\delta^{15} \mathrm{~N}$ signatures along the length of their growing primaries, indicating they were molt-migrants, while the third, presumably a resident, showed no change. We then resampled these feathers at closer intervals for evidence of the predicted diel cycle in the use of exogenous and endogenous protein for feather growth, generated by the diel feeding cycle of these geese. As predicted, the two geese that were equilibrating to a new isoscape showed oscillations of approximately 24-hour periodicity in $\delta^{15} \mathrm{~N}$ values, measured along the length of their primaries. In contrast, the goose that was not equilibrating to a new isoscape showed no 24 -hour periodicity in its $\delta^{15} \mathrm{~N}$ values. Our results demonstrate that chronological sampling along the length of individual primaries holds great potential for identifying individuals that are molt-migrants. 
Sievert Rohwer ${ }^{1,5}$, Anthony D. Fox ${ }^{2}$, Thomas Daniel ${ }^{3}$, Jeffery F. Kelly ${ }^{4}$

${ }^{1}$ Department of Biology and Burke Museum, University of Washington, Seattle, WA, 98195, USA; rohwer@uw.edu

${ }^{2}$ Department of Bioscience, University of Aarhus, Kalø, Grenåvej 14, DK-8410, Rønde, Denmark; tfo@dmu.dk

${ }^{3}$ Department of Biology, University of Washington, Seattle, WA, 98195, USA; danielt@uw.edu

${ }^{4}$ Oklahoma Biological Survey and Department of Biology, University of

Oklahoma, 111 E. Chesapeake St, Norman, OK 73019, USA; ikelly@ou.edu

${ }^{5}$ Corresponding author: rohwer@uw.edu 


\section{INTRODUCTION}

11 1990).

12 These facts generate two predictions that help identify molt-migrants 13 that initiate feather growth shortly after moving to a new isoscape. First, 14 molt-migrants that begin molt before equilibrating to a new isoscape should 15 show a steady change in isotope signature along the length of their flight 16 feathers. This prediction is easily tested with course sampling along the 17 length of flight feathers. Second, if local exogenous protein sources are 18 exhausted between bouts of feeding, fine sampling along feathers, should 19 reveal a roughly 24-hour periodicity representing the alternating use of 20 exogenous and endogenous protein for feather construction. The amplitude 21 of this cycle is likely driven by the size of the protein pool in the blood 22 relative to the amount of protein being withdrawn for feather synthesis.

23 Depending on the fraction of blood protein used for feather synthesis, daily

24 feeding and fasting should generate measurable (if sometimes small) 25 changes.

26 Greylag Geese (Anser anser) that breed in terrestrial, freshwater

27 habitats in Sweden are known to migrate in late summer to the maritime 28 saltmarshes of the island of Saltholm $\left(55^{\circ} 38^{\prime} \mathrm{N} 12^{\circ} 45^{\prime} \mathrm{E}\right.$, Nilsson et al. 2001)

29 in Denmark where they undergo their annual molt while grazing on saltmarsh 30 plants (Fox et al. 1995, Fox et al. 1998). Compared to freshwater

31 environments, marine environments are known to have very different $\delta^{15} \mathrm{~N}$

32 signatures, and they may have slightly different $\delta^{13} \mathrm{C}$ signatures. 
33 Correspondingly, stable isotope values in growing flight feathers of Greylag

34 Geese were intermediate between birds on a terrestrial plant diet and those 35 on a saltmarsh diet (Fox et al. 2009).

To explore expected changes in $\delta^{15} \mathrm{~N}$ and $\delta^{13} \mathrm{C}$ along the length of

37 primaries and to examine the potential for 24-hour cycling in the use of 38 exogenous and endogenous protein for feather growth, we serially sampled a 39 single primary feathers from each of three Greylag Geese from Saltholm; 40 these feathers (and no others) were available from the study of Fox et al.

41 (2009). Because feathers are generated from tip to base and composed of 42 non-living keratin, primaries grown by geese that migrated to Saltholm for 43 their molt should change chronologically from more positive (freshwater) $\delta^{15} \mathrm{~N}$ 44 signatures at the feather tip to more negative (marine) $\delta^{15} \mathrm{~N}$ signatures 45 toward the feather base. Further, because flightless Greylag Geese forage 46 only at night on Saltholm (Kahlert et al. 1996), a 24-h periodicity in the $\delta^{15} \mathrm{~N}$ 47 signature should be expected in serial samples from the flight feathers of 48 geese that were not in equilibrium with the Saltholm isoscape.

49 Our results show that serial samples taken along the length of primary 50 flight feathers readily show equilibration toward a new isoscape and, further,

51 that feathers sampled at fine intervals can reveal diel shifts in exogenous and 52 endogenous protein sources used for feather generation. These results 53 clearly demonstrate that the chronological samples available from individual 54 feathers can be used to identify individuals that are molt migrants. We are 55 aware of just two prior studies of hair or feathers that used chronological 56 samples to examine changes in isotope signatures through time. Cerling et 57 al. (2006) used elephant hair to demonstrate the movement of individual 58 African elephants (Loxodonta africana) to different foraging locations, and 59 Church et al. (2006) used samples along the length of a growing rectrix from 60 a California Condor (Gymnogyps californianus) to show a sudden deposition 61 of lead that resulted in its death. Because our results are unavoidably based 62 on feathers from just three geese, their importance lies in demonstrating the 63 value of chronological samples to study molt-migrantion in birds. 


\section{MATERIALS AND METHODS}

65 Feathers were obtained from Greylags in active molt on Saltholm, between 66 Copenhagen and Swedish Skania coast (Fox et al. 2009). The Danish Forest

67 and Nature Agency gave permission to catch and sample the geese and the

68 landowners of Saltholm gave permission to work on the island. The geese 69 were caught under the Copenhagen University Natural History Museum 70 Ringing Permit A600 “DMU-Kalø Ringmærkning."

71 The geese included in this study were not individually tracked, so we do

72 not know when they arrived at Saltholm, or how soon after arrival they

73 started to molt, or even if they were all molt-migrants to Saltholm. These

74 limitations mean that useful information on periodicity could only come only

75 from birds that showed declining $\delta^{15} \mathrm{~N}$ signatures along the length of the 76 sampled primary, indicating they were molt-migrants to Saltholm. Greylags 77 are large geese that would require considerably more than a month to come 78 into equilibrium with the new isoscape of Saltholm (Martinez del Rio and 79 Anderson-Sprecher 2008). Molting geese in equilibrium with the salt marsh 80 isoscape of Saltholm should show no 24-hour cycling in isotopic signatures;

81 these could be either local, Saltholm, geese (e.g. failed breeders) or salt 82 marsh breeders from a similar isoscape. Although there is variation among 83 individual feather growth rates, Greylag Geese should grow their feathers at 84 approximately $7 \mathrm{~mm} \mathrm{~d}^{-1}$, as inferred from a mean mass of $3509 \mathrm{~g}$ (Dunning 85 2007) and the allometric relationship between primary growth rate and body 86 size (Rohwer et al. 2009).

87 The feathers used for this study were sampled twice, first $5 \mathrm{~mm}$ 88 intervals from the tip of the primary to measure change in $\delta^{15} \mathrm{~N}$ and $\delta^{13} \mathrm{C}$ over 89 long time periods, and second, at 1 or $2 \mathrm{~mm}$ intervals, to assess $24 \mathrm{~h}$ 90 periodicity in the protein source used for feather generation. Which primary

91 feather was used should not affect the results of this study, as Greylag

92 Geese, like most waterfowl, lose and replace their flight feathers 93 simultaneously (Hohman et al. 1992).

$94 \quad$ Methods for sample preparation and analysis generally follow those in 95 Paritte and Kelly (2009). Feathers were cleaned in dilute detergent followed 
96 by repeated rinsing. After air drying the feathers were cleaned again in 2:1

97 chloroform:methanol and allowed to air dry before processing. Once feathers 98 were dried a research technician marked the rachis of each feather from its 99 tip to the base of the growing vane at 1,2 or $5 \mathrm{~mm}$ intervals. The majority of 100 the posterior vane was then cut away, leaving only the few $\mathrm{mm}$ closest to the 101 rachis. Then, using the pen marks as a guide, an approximately $200 \mu \mathrm{g}$ 102 sample of feather vane was cut immediately adjacent to the pen mark.

103 These samples were loaded into tin capsules $(3.5 \times 5.5 \mathrm{~mm})$ and stored in an 104 elisa plate until they were analyzed.

105 We analyzed samples in batch sequences of 49 samples and 106 references, referred to as autoruns. Each autorun typically analyzed 39 107 unknown samples and 8 laboratory reference samples in positions 1, 2, 7, 13, 108 19, 37, 43, 49. The laboratory reference material was powdered Brown109 headed Cowbird feather (Molothorus ater), as described in Kelly et al. (2009).

110 Among sample variation in the laboratory reference material was $<0.2 \%$ o for

111 both $\delta^{13} \mathrm{C}$ and $\delta^{15} \mathrm{~N}$. In addition, to this laboratory reference we ran one 112 sample each of two National Institute of Standards and Technologies NIST 113 reference materials (USGS 40 in autorun position 25 and USGS 41 in autorun 114 position 31 ). All stable isotope ratios are expressed in standard $\delta$ notation, 115 where $\delta^{13} \mathrm{C}$ and $\delta^{15} \mathrm{~N}=$ [(isotope ratio sample/isotope ratio standard) - 1] * 116 1000. Consequently, $\delta^{13} \mathrm{C}$ and $\delta^{15} \mathrm{~N}$ are expressed in parts per thousand (\%o) 117 deviations from a standard, which was Vienna Pee Dee Belemnite for $\delta^{13} \mathrm{C}$ 118 and air for $\delta^{15} \mathrm{~N}$. Isotope ratios were measured at the University of Oklahoma 119 using a Thermo Finnigan Delta $\mathrm{V}$ isotope ratio mass spectrometer connected 120 to a CosTech elemental analyzer.

121 For each autorun we corrected all measurements for instrumental drift 122 between the first and last sample. Instrumental drift corrections were based 123 on the slopes of best-fit lines for $\delta^{13} \mathrm{C}$ and $\delta^{15} \mathrm{~N}$ values regressed against

124 analysis time of references within each autorun. A slope was calculated for

125 the cowbird standard in the run and this slope was used as the drift

126 correction coefficient. 
127 To determine if there was evidence of 24-hour cycling in the $\delta^{15} \mathrm{~N}$ values 128 along the length of the primaries, we used custom Matlab code to perform an 129 autocorrelation analysis after de-trending the data using linear regression

130 and removing the mean. We used this method to find correlation maxima

131 and minima that reveal periodicity in the $\delta^{15} \mathrm{~N}$ values. Using additional

132 custom Matlab code, we then developed a bootstrap method to test for the

133 statistical significance of having autocorrelation minima and maxima that

134 correspond to a periodic pattern in isotope values. To do so, we randomly 135 permuted the data for each feather and performed autocorrelation analyses

136 of those permuted values. Out of 10,000 permutations, we asked what

137 fraction of the data had both a minimum less than or equal that observed in

138 our original autocorrelation and a maximum spaced at the appropriate

139 interval.

\section{RESULTS}

\section{Evidence for equilibration following molt-migration}

$142 \delta^{15} \mathrm{~N}$ signatures declined over time in two geese (501 and 508, $\mathrm{P}<0.0001$ ),

143 while 509, showed no change $(P=0.34$, Fig. 1$)$. Both geese that changed did 144 so in a way consistent with the large shift of about $8 \%$ in the $\delta^{15} \mathrm{~N}$ isoscapes 145 suggested by the results of Fox et al. (2009). $\delta^{15} \mathrm{~N}$ was constant, with a mean 146 of $7.6 \%$, along the primary for goose 509 , which is puzzling because this 147 mean is intermediate between the beginning and ending values for the other 148 two geese (Fig. 1). If this individual had been on Saltholm long enough to be 149 in equilibrium with the salt marsh isoscape, then its mean $\delta^{15} \mathrm{~N}$ value should 150 have been at or below the latest values from the two geese that showed 151 declining $\delta^{15} \mathrm{~N}$ values. That its mean $\delta^{15} \mathrm{~N}$ was considerably higher than the 152 lowest $\delta^{15} \mathrm{~N}$ values found for the two geese coming into equilibrium (Fig. 1), 153 suggest it was a resident goose that did not feed in the Saltholm salt

154 marshes. Hayfields used by resident Greylag Geese are less subject to 155 marine influence than the saltmarshes where the majority of migrants feed.

156 The results of Fox et al. (2009) suggest that $\delta^{13} \mathrm{C}$ signatures of molt 157 migrant geese should decline if they moved from Sweden to Saltholm for the 
158 molt. Yet, the $\delta^{13} \mathrm{C}$ signature of goose 501 increased along the length of its

159 primary $(p=0.0003)$, while $\delta^{13} \mathrm{C}$ showed no change for $509(p=0.09)$ and

160508 ( $p=0.46$, Fig. 1 ). The decline in $\delta^{15} \mathrm{~N}$ for goose 501 strongly support its

161 being a molt migrant to the island of Saltholm because freshwater and

162 marine signatures for $\delta^{15} \mathrm{~N}$ are very different; yet, its $\delta^{13} \mathrm{C}$ increased through

163 time (Fig. 1), contrary to expectation from the results of Fox et al. (2009).

\section{Evidence for 24 hour cycling in $\delta^{15} \mathrm{~N}$}

165 Flightless Greylag Geese forage at night on Saltholm (Kahlert et al. 1996).

166 Thus, we predicted and found a 24-hour periodicity in the $\delta^{15} \mathrm{~N}$ signature from

167 chronological found samples of the two geese $(501,508)$ coming into

168 equilibrium with the Saltholm marine environment (Fig. 2). In contrast, N was

169 constant along the length of the primary in 509, as expected for a resident

170 goose in equilibrium with its diet. Because of sampling problems and a

171 malfunction of the mass spectrophotometer, these fine-resolution runs

172 covered fewer days than the regression analyses, which should tend to make

173 periodicity in the data harder to demonstrate.

174 The $\delta^{15} \mathrm{~N}$ signal is not purely periodic in any of the sampled feathers

175 because of sampling noise. Feather 508 shows a minimum (most negative)

176 autocorrelation value at the second autocorrelation lag. Given a sampling

177 interval of $2 \mathrm{~mm}$, this corresponds to $4 \mathrm{~mm}$ of feather length. Additionally,

178508 showed positive autocorrelation values in the region of twice the

179 minimum, strongly indicating periodicity in the data. The bootstrap statistics

180 indicated that the probability of having the combination of a minimum at the

181 lag of 2 and a max near the lag of 4 is $p=0.032$. Feather 501 had a different

182 sampling interval and, accordingly, showed a more expanded autocorrelation

183 function with a minimum at lag of 3 and a maximum autocorrelation at twice

184 that value. The bootstrap probability of having that combined maximum and

185 minimum was $p=0.01$. Thus, feathers 501 and 508 both show significant

186 periodicity in their $\delta^{15} \mathrm{~N}$ values. In contrast, feather 509 , which showed no

187 sign of coming into a new equilibrium for $\delta^{15} \mathrm{~N}$, showed no significant change 
188 in sign for the autocorrelation, suggesting, as predicted, that there was no 189 periodic signal in the serial $\delta^{15} \mathrm{~N}$ values for this feather.

\section{DISCUSSION}

\section{The value of sampling feathers serially}

192 As far as we are aware, the data for $\delta^{15} \mathrm{~N}$ in Figure 1 constitute the first direct

193 test of a gradual change in the isotopic composition of feathers being grown

194 while a molt-migrant is coming into equilibrium with a new isoscape. Fox et

195 al. (2009) inferred this process by sampling food plants used by Greylag

196 Geese on their breeding grounds in southern Sweden, and on their saltwater

197 molting grounds on the island of Saltholm in Denmark. This inference was

198 based on the assumption that fractionation values for the conversion of $\delta^{15} \mathrm{~N}$

199 values in food plants to $\delta^{15} \mathrm{~N}$ values in goose feathers were accurately

200 represented by the results of an experimental study of Japanese Quail

201 (Coturnix japonica) raised on a plant based diet (Hobson and Clark 1992a;

202 Hobson and Clark 1992b). How well those values represent similar processes

203 in Greylag Geese is an unknown, as are the confidence intervals associated

204 with these transformations. Further, Fox et al. (2009) used only two food

205 plants from each locality to infer the expected changes in $\delta^{15} \mathrm{~N}$ and $\delta^{13} \mathrm{C}$

206 values for feathers, yet Greylag Geese probably use a larger diversity of

207 plants at each of these localities, as is known for molting Saltholm geese (Fox

208 et al. 1998). The direct measure of change for $\delta^{15} \mathrm{~N}$ for two of the three

209 Greylag primaries in our sample offers a powerful confirmation of the result

210 obtained by Fox et al. (2009). The mean value of $8.4 \%$ o for $\delta^{15} \mathrm{~N}$ for feathers

211 from 12 molting geese (Fox et al. 1998) is reasonably close to the mean of

$2127.6 \%$ o for the two geese that were equilibrating with the Saltholm

213 environment. Mean $\delta^{15} \mathrm{~N}$ for the goose that showed no evidence of

214 equilibrating was also 7.6\%o (509), considerably higher than the latest (most

215 proximal) $\delta^{15} \mathrm{~N}$ values for the two geese that were equilibrating (Fig. 1). The

216 relatively high mean $\delta^{15} \mathrm{~N}$ for goose 509 , together with the lack of change in

$217 \delta^{15} \mathrm{~N}$ along its feather, suggests that this goose had not arrived early and 
218 delayed the start of its molt until reaching equilibrium with the Saltholm

219 isoscape. Possibly it was a Saltholm resident with a different diet.

220 Fox et al. (2009) suggested that $\delta^{13} \mathrm{C}$ also changed in a way that

221 suggested the use of endogenous carbon in the generation of primary

222 feathers during the molt. However, the absolute difference in the expected

223 values for $\delta^{13} \mathrm{C}$ (again, generated by sampling two food plants from the

224 Swedish breeding grounds and two food plants from the Saltholm molting

225 grounds) was less than $2 \%$. While mass spectrometers can readily measure

226 differences as small as $2 \%$, predicting differences this small by applying

227 fraction values to the $\delta^{13} \mathrm{C}$ values measured to samples of two food plants

228 consumed by geese at their breeding and molting sites seems hazardous.

229 With their sample of 12 geese, Fox et al. (2009) did find the feather values to

230 be intermediate between the food values for Sweden and Saltholm, using the

231 conversion figures for Japanese Quail (Hobson and Clark 1992b). Our mean

$232 \delta^{13} \mathrm{C}$ value of $-26.2 \%$ for the three feathers we analyzed is close to their

233 mean of $-26.5 \%$ based on 12 geese (Fox et al. 2009). However, the results

234 of Fox et al. (2009) suggest that $\delta^{13} \mathrm{C}$ values should decline during primary

235 growth but, we found no evidence for such a decline: two geese showed no

236 change, while the third showed a significant increase in $\delta^{13} \mathrm{C}$ along the length

237 of its primary (Fig. 1). Further, goose 501 that showed an increase in $\delta^{13} \mathrm{C}$

238 values showed a strong decline in $\delta^{15} \mathrm{~N}$ values along the length of its growing

239 primary, indicating it was not yet in equilibrium with the Saltholm $\delta^{15} \mathrm{~N}$

240 isoscape. The positive slope for $\delta^{13} \mathrm{C}$ in this goose further suggests that the

241 expected difference in feather $\delta^{13} \mathrm{C}$, estimated from food plants sampled in

242 Sweden and Saltholm (Fox et al. 2009), was not reliable.

\section{Stored reserves and 24-hour cycling}

244 The two geese that showed declines in $\delta^{15} \mathrm{~N}$ along their primaries also

245 showed 24 -hour cycling in their $\delta^{15} \mathrm{~N}$ values, as predicted. Further, the goose

246 that showed no change in $\delta^{15} \mathrm{~N}$ along its primary showed no evidence of 24-

247 hour cycling, which was predicted because it was not coming into equilibrium

248 with the $\delta^{15} \mathrm{~N}$ environment of Saltholm. These results support the use of 
249 endogenous reserves for feather growth during parts of the 24-hour cycle

250 when geese do not forage and feathers continue to grow (Murphy and King

251 1990). The periodicity of this cycling corresponds to primary growth rates of

252 roughly 8 and $6 \mathrm{~mm} \mathrm{~d}^{-1}$ for feathers 509 and 501, respectively. These inferred

253 rates of primary growth accord well with a growth rate of about $7 \mathrm{~mm} \mathrm{~d}^{-1}$ for a

254 bird the size of a Greylag Goose (Rohwer et al. 2009).

$255 \quad$ Although little of biological importance can be concluded from three

256 geese, it is important to emphasize that we could think of no alternative

257 hypothesis that could account for 1 ) the concordance we found between

258 equilibration and 24 hour cycling in the use of exogenous and endogenous

259 protein sources for feather generation, and 2) the period of this cycling

260 matching the expected primary growth rate for Greylag Geese. Finer

261 sampling, that could be achieved with laser ablation, presumably would

262 eliminate the noise in our autocorrelation results resulting from 1 or $2 \mathrm{~mm}$

263 sampling intervals, leaving only noise associated with day-to-day differences

264 in food intake and feeding times (Moran et al. 2011).

\section{General}

266 Bridge et al. (2011) assessed the possible use of endogenous protein

267 reserves for molting by studying changes in $\delta D$ and $\delta^{13} \mathrm{C}$ in the primaries of

268 Painted Buntings (Passerina ciris). Like many other migrant song birds that

269 breed in the central and southern regions of western North America, Painted

270 bunting from the Midwestern breeding population migrate to northwest

271 Mexico for their annual post-breeding molt (Thompson 1991; Rohwer et al.

272 2005; Rohwer 2013). Here they exploit a food flush generated by the late

273 summer monsoon, which delivers most of the annual precipitation to this

274 region in July - September (Adams and Comrie 1997; Comrie and Glenn

275 1998). Primary replacement in Painted Buntings in Sinaloa is so rapid that it

276 requires an average of only 30 and 34 days in adult females and adult males,

277 respectively (Rohwer 2013).

$278 \quad$ Bridge et al. (2011) showed that both $\delta D$ and $\delta^{13} \mathrm{C}$ values changed from

279 primary 1 to 9 in some Painted Buntings sampled in Sinaloa. They suggest 
280 that birds with differences between primaries 1 and 9 should be individuals

281 that had initiated molt shortly after arriving in Sinaloa, before their

282 endogenous protein reserves reached equilibrium with the Sinaloa isoscape.

283 Individuals without strong differences between these primaries either may

284 have delayed molt until their endogenous protein reserves were in

285 equilibrium with the Sinaloa isoscape, or the food they consumed before

286 migrating may have matched what they were consuming on their Sinaloa

287 molting grounds. Direct evidence of continuous change in $\delta D$ and $\delta^{13} C$ is

288 needed to test the suggestion by Bridge et al. (2011) that those buntings

289 with strong differences in $\delta \mathrm{D}$ and $\delta^{13} \mathrm{C}$ signatures between primaries 1 and 9

290 were coming into equilibrium with a new isoscape while molting. This could

291 now be accomplished by sampling across different primaries on the feather-

292 time axis developed by Rohwer and Broms (2012), which spans the

293 replacement of all primaries.

294 In general, measuring isotopic changes in chronological samples taken

295 at equal intervals from flight feathers offers a powerful tool for studying molt-

296 migration. It provides strong data for individual birds while avoiding the

297 assumptions involved with food sampling and using fraction estimates to

298 compute expected tissue values for isotopes. Serial samples representing

299 equal time intervals through primary growth can be generated in two ways.

300 For large birds, finely spaced samples along the length of a primary are

301 chronologically so accurate that they can be used, not only to assess isotopic

302 change during feather growth, but also to evaluate the expected 24-hour

303 periodicity in isotope measurements driven by foraging schedules. For small

304 birds with short primaries, serial samples from single primaries would

305 generate only a limited temporal series and their primaries grow so slowly

306 (Rohwer et al. 2009) that sampling with laser ablation would be required to

307 achieve a sample density sufficient to detect 24-hour cycling (Moran et al.

308 2011). Nonetheless, samples representing approximately equal time

309 intervals across the full primary molt can be taken from different primaries

310 (Rohwer and Broms 2012). Sampling across the full chronology of primary

311 replacement extends the sampling period enough that changes in isotopes 
312 during primary growth should reliably identify individual molt-migrants, even

313 in small birds.

\section{ACKNOWLEDGMENTS}

315 Thanks to the Øresund Consortium for financial support of the original

316 fieldwork, the Danish Forest and Nature Agency for permission to catch and

317 sample geese, the landowners of Saltholm for permission to work on the

318 island, Niels Adamsen for his practical help and Ebbe Bøgebjerg and Jens

319 Peter Hounisen for catching molting geese. Thanks also to Johnny Kahlert for

320 assistance, support and inspiration, to Sarah Engel for serially sampling the

321 feathers, and to Jared Grummer for help with the figures. Comments from

322 James Roper and André Guaraldo helped improve the manuscript. Special

323 thanks to Peerj for its new model of open access publishing.

\section{REFERENCES}

325 Adams, D. K., and A. C. Comrie. 1997. The North American Monsoon. Bulletin 326 of the American Meterological Society 78:2197-2213.

327 Bridge, E. S., F. A. M., K. J. F., C. A., and S. Rohwer. 2011. Causes of bimodal 328 stable isotope signatures in the feathers of a molt-migrant songbird.

329 Canadian Journal of Zoology 89:951-959.

330 Cerling, T. E., G. Wittemyer, H. B. Rasmussen, F. Vollrath, C. E. Cerling, T. J.

331 Robinson, and I. Douglas-Hamilton. 2009. Stable isotopes in elephant hair 332 document migration patterns and diet changes. Proceedings of the 333 National Academy of Science, USA 103:371-373.

334 Church, M. E., R. Gwiazda, R. W. Risebrough, K. Sorenson, C. P. Chamberlain,

335 S. Farry, W. Heinrich, B. A. Rideout, and D. R. Smith. Ammunition is the principal source of lead accumulated by California Condors re-introduced into the wild. Environmental Science and Technology 40:6143-6150.

Comrie, A. C., and E. C. Glenn. 1998. Principal components-based regionalization of precipitation regimes across the southwest United States and northern Mexico, with an application to monsoon precipitation variability. Climate Research 10:201-215. 
342 Dunning, J. B., Jr. 2007. CRC Handbook of Avian Body Masses, Second ed. CRC 343 Press, London.

344 Fox, A. D., K. A. Hobson, and J. Kahlert. 2009. Isotopic evidence for 345 endogenous protein contributions to Grelag Goose Anser anser flight 346 feathers. Journal of Avian Biology 40:108-112.

347 Fox, A. D., J. Kahlert, and H. Ettrup. 1998. Diet and habitat use of moulting 348 Greylag Geese Anser anser on the Danish island of Saltholm. Ibis 349 140:676-683.

350 Fox, A. D., J. Kahlert, H. Ettrup, L. Nilsson, and J.-P. Hounisen. 1995. Moulting 351 Greylag Geese on the Danish island of Saltholm; numbers, phenology, 352 status and origins. Wildfowl 46:16-30.

353 Hobson, K. A., and R. G. Clark. 1992a. Assessing avian diets using stable 354 isotopes. 2. Factors influencing diet-tissue fractionation. Condor 94:189355197.

356 Hobson, K. A., and R. G. Clark. 1992b. Assessing avian diets using stable 357 isotopes. I: Turnover of carbon-13 in tissues. Condor 94:181-188.

358 Hohman, W. L., C. D. Ankney, and D. H. Gordon. 1992. Ecology and 359 management of postbreeding waterfowl. Pages 128-189 in Ecology and management of breeding waterfowl. (B. D. J. Batt, A. D. Afton, M. G. Anderson, C. D. Ankney, D. H. Johnson, J. A. Kadlek, and G. L. Krapu, Eds.). University of Minnesota Press., Minneapolis.

Kahlert, J., A. D. Fox, and H. Ettrup. 1996. Nocturnal feeding in moulting Greylag Geese Anser anser - an anti-predator response? Ardea 84:15-22.

Kelly, J. F., E. S. Bridge, A. M. Fudickar, and L. I. Wassenaar. 2009. A test of comparative equilibration for determining non-exchangeable stable hydrogen isotope values in complex organic materials. Rapid Communications in Mass Spectrometry 23:2316-2320.

Lillie, F. R., and W. H. 1940. Physiology of development of the feather: IV. The diurnal curve of growth in the brown leghorn fowl. Proceedings of the National Academy of Science, USA 26:67-85. 
372 Martinez del Rio, C., and R. Anderson-Sprecher. 2008. Beyond the reaction

373 progress variable: the meaning and significance of isotope incorporation 374 data. . Oecologia 156:765-772.

375 Moran, J. J., M. K. Newburn, M. L. Alexander, R. L. Sams, J. F. Kelly, and H. W.

$376 \quad$ Kreuzer. 2011. Laser ablation isotope ratio mass spectrometry for

377 enhanced sensitivity and spatial resolution in stable isotope analysis.

378 Rapid Communications in Mass Spectrometry 25:1282-1290.

379 Murphy, M. E., and J. R. King. 1986. Diurnal constancy of feather growth-rates

380 in White-crowned Sparrows exposed to various photoperiods and feeding

381 schedules during the postnuptial molt. Canadian Journal of Zoology-

382 Revue Canadienne De Zoologie 64:1292-1294.

383 Murphy, M. E., and J. R. King. 1990. Diurnal changes in tissue glutathione and 384 protein pools of molting White-crowned Sparrows - the influence of photoperiod and feeding schedule. Physiological Zoology 63:1118-1140.

Nilsson, L., J. Kahlert, and H. Persson. 2001. Moult and moult migration of Greylag Geese Anser anser from a population in Scania, South Sweden. Bird Study 48:129-138.

Paritte, J. M., and J. F. Kelly. 2009. Effect of cleaning regime on stable-isotope ratios of feathers in Japanese Quail (Coturnix japonica). Auk 126:165-174.

Rohwer, S. 2013. Molt Intensity and Conservation of a Molt-migrant (Passerina ciris) in Northwest Mexico. Condor 115:421-433.

Rohwer, S., and K. Broms. 2012. Use of feather lopss intervals to estimate molt duration and to sample feather vein at equal time intervals throughout the primary replacement. Auk 129:653-659.

Rohwer, S., L. K. Butler, and D. R. Froehlich. 2005. Ecology and demography of east-west differences in molt scheduling in Neotropical migrant passerines. Pages 87-105 in Birds of Two Worlds (R. Greenberg, and P. P. Marra, Eds.). Johns Hopkins University Press, Baltimore.

Rohwer, S., R. E. Ricklefs, V. G. Rohwer, and M. M. Copple. 2009. Allometry of the duration of flight feather molt in birds. PLoS Biology 7:e1000132. 
402 Schieltz, P. C., and M. E. Murphy. 1995. Diurnal variation in oxygen

403 consumption by molting and nonmolting sparrows. Comparative

404 Biochemistry and Physiology a-Physiology 112:265-272.

405 Thompson, C. W. 1991. The sequence of molts and plumages in Painted

406 Buntings and implications for theories of delayed plumage maturation.

407 Condor 93:209-235. 
1

Values for $\delta^{15} \mathrm{~N}$ and $\delta^{13} \mathrm{C}$ measured in serial samples along the length of the primary.

Feather vein was sampled at $5 \mathrm{~mm}$ intervals near the rachis of the growing primary for its full length, starting at the tip of the feather. 

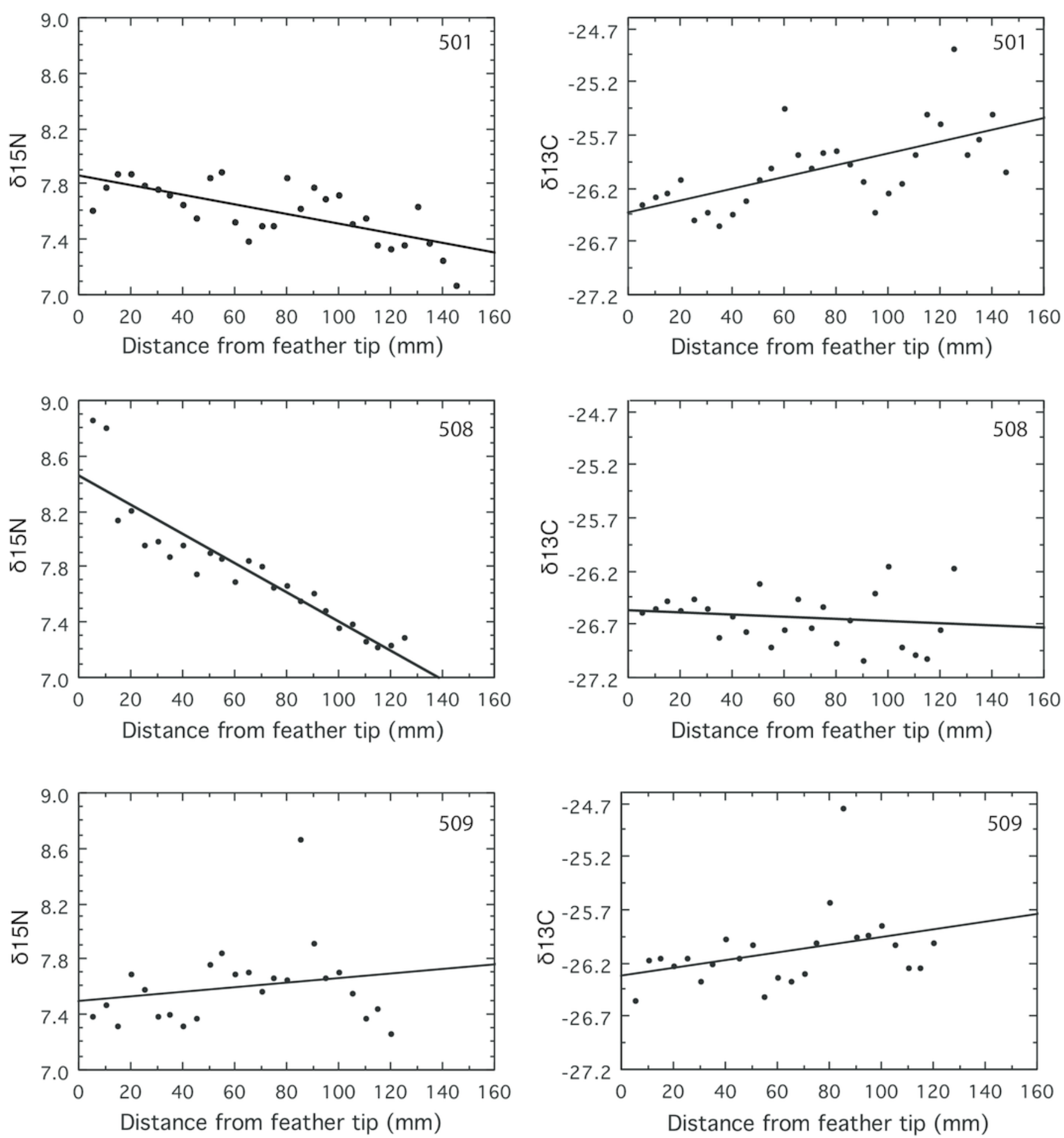
2

Autocorrelation and regression results for ${ }^{15} \mathrm{~N}$ measured at 1 or $2 \mathrm{~mm}$ intervals from the tips of growing primaries.

Greylag Geese 501 and 508 showed decreasing $\delta^{15} \mathrm{~N}$ values, indicating they were equilibrating with the Saltholm isoscape while their primaries were growing, and both showed significant autocorrelations ( $p=0.01$ and 0.03 , respectively). Goose 509 showed no change in its $\delta^{15} \mathrm{~N}$ values and no autocorrelation $(p>0.25)$. 

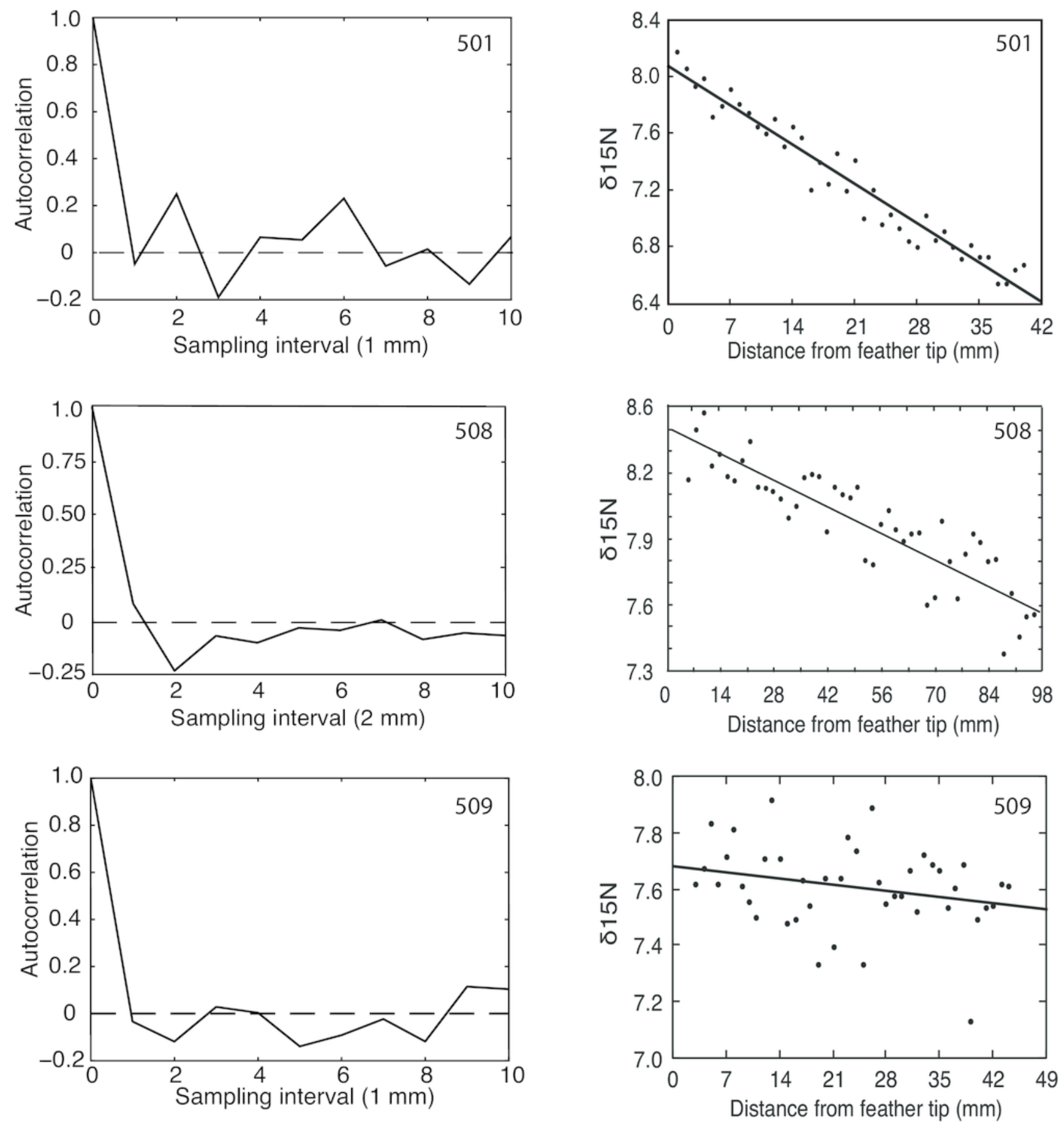